\title{
Call for Nominations: IUPAP Young Scientist Prize in Low Temperature Physics 2011
}

Published online: 1 May 2010

(C) Springer Science+Business Media, LLC 2010

Nominations are being sought for the Young Scientist Prize in Low Temperature Physics, which will be awarded by the International Union of Pure and Applied Physics through the Commission C5 (Low Temperature Physics) in 2011. The prize will be awarded during the 26th International Conference on Low Temperature Physics (LT26) to be held in Beijing, China, August, 2011. The Prize includes a medal, a \$1000 award and an invited presentation to be made at LT26.

The nominee is expected to have made original and outstanding contributions to the field of low temperature physics. If the work was performed in collaboration, the leading personal contribution of the recipient to the achievement must be clearly identifiable. Nominees for the prize should by January 15, 2011 have a maximum of 8 years of research experience (excluding career interruption) following the $\mathrm{PhD}$.

Nominations should include:

- A letter of not more than 1,000 words evaluating the nominee's achievements and identifying the specific work to be recognized.

- Curriculum vitae that identifies all publications.

- A brief biographical sketch not to exceed two pages.

- Suggested text for the award citation.

Self-nominations will not be considered. Nominations should be sent to the chair of IUPAP C-5: preferably by e-mail with attachments (e-mail: hallock@physics.umass. edu); or by regular mail (Prof. R.B. Hallock, Department of Physics, 666 North Pleasant St., University of Massachusetts, Amherst, MA, 01003, USA).

Deadline for receipt of nominations is January 15, 2011. 